\title{
Kinetic Model of Thermal Degradation of Polymers for Nonisothermal Process
}

\author{
BAR-LONG DENQ, WEN-YEN CHIU, KING-FU LIN \\ Institute of Materials Science and Engineering, National Taiwan University, Taiwan, Republic of China
}

Received 5 December 1996; accepted 30 December 1996

\begin{abstract}
A new kinetic model was developed to describe the thermal degradation behavior of polymers. The model was applied to predict the degradation of poly (methyl methacrylate) (PMMA) blended with propyl ester phosphazene (FR). The results showed that the thermal degradation mechanism of pure PMMA was dominated by zero- and first-order reactions. For PMMA blended with FR, the thermal degradation mechanism was dominated by first- and second-order reactions due to the formation of anhydride from the ester groups of PMMA. In addition, the major thermal degradation temperature of blends was greater than pure PMMA. By using our model, the activation energy of the thermal degradation PMMA was calculated to be $180 \mathrm{~kJ} / \mathrm{mol}$; this activation energy increased as FR was added to PMMA. (C) 1997 John Wiley \& Sons, Inc. J Appl Polym Sci 66: 1855-1868, 1997
\end{abstract}

Key words: poly(methyl methacrylate); propyl ester phosphazene; thermal degradation kinetics

\section{INTRODUCTION}

The thermal degradation kinetics in polymers are more complicated than in inorganic materials due to the nature of polydispersity of polymer chains. Upon thermal excitation, the covalent bonds in polymer chains undergo complex vibration and rotation motions within their local space. With further excitation these bonds can break to form a variety of fragment radicals or small molecules, which may further mutually recombine or break. Ultimately, the resulting fragments may be vaporized, diffused out, or carbonized. The thermal behavior of materials can be improved if the information about the thermal degradation kinetics and degradation mechanisms can be employed to decrease the thermal degradation rate or increase the heat resistance.

Thermogravimetric analysis (TGA) is an excel-

\footnotetext{
Correspondence to: W.-Y. Chiu.

Contract grant sponsor: Chung Shan Institute of Science and Technology (CSIST), Taiwan, R.O.C.

Journal of Applied Polymer Science, Vol. 66, 1855-1868 (1997) (C) 1997 John Wiley \& Sons, Inc. CCC 0021-8995/97/101855-14
}

lent tool for studying the kinetics of thermal degradation. It provides information on frequency factor, activation energy, and overall reaction order. ${ }^{1-5}$ Unfortunately, it does not provide clear information on thermal degradation mechanisms.

One compelling model of thermal degradation is the model, proposed by Ozawa ${ }^{6}$ in 1993, of nonisothermal competitive reactions based on the concept of reduced times. The model treats the conversion of reactant as being dependent only on the sum of the reduced times of the reactions involved and as being independent of the path of the process or the temperature change. This model has not been fully supported by the literature on the thermal degradation mechanism, however, which indicated that the degradation behavior also depends on the experimental conditions, such as heating rate, atmosphere, sample size, and sample geometry. In this work we have developed a model which accounts not only for the effects of parallel competitive reactions but also for the effects of multi-order combined reactions. This model is applied to the thermal degradation behavior of poly(methyl methacrylate) (PMMA) 
Table I Physical Properties of PMMA and Propyl Ester Phosphazene

\begin{tabular}{|c|c|c|c|c|}
\hline Materials & Formula & $\begin{array}{c}T_{g}^{\mathrm{a}} \\
\left({ }^{\circ} \mathrm{C}\right)\end{array}$ & $\begin{array}{l}\text { Melt Flow Index } \\
\qquad(\mathrm{g} / 10 \mathrm{~min})\end{array}$ & Remarks \\
\hline PMMA & $+\mathrm{CH}_{2}-\stackrel{\left.\mathrm{CH}_{3}^{\mathrm{C}}\right)_{n}}{\mathrm{CO}}$ & 110 & $14^{\mathrm{b}}$ & CM-211 \\
\hline Propyl ester phosphazene & $+\mathrm{N}={\stackrel{\mathrm{O}}{\mathrm{P}})_{n}}_{\mathrm{OC}_{3} \mathrm{H}_{7}}^{\mathrm{OC}_{3} \mathrm{H}_{7}}$ & -100 & $\mathrm{c}$ & $\begin{array}{l}\text { Cyclic/linear } \\
\text { Structure = } 65: 35 \\
\mathrm{Cl}<0.1 \text { wt } \%\end{array}$ \\
\hline
\end{tabular}

${ }^{a}$ Determined by differential scanning calorimetry.

${ }^{\mathrm{b}}$ By ASTM Code D-1238.

${ }^{\mathrm{c}}$ Viscosity $>10^{6}$ poise $\left(25^{\circ} \mathrm{C}\right)$.

and PMMA blended with propyl ester phosphazene (FR). The model's insights into the thermal degradation kinetics and mechanisms of PMMA and PMMA/FR blends are also discussed.

\section{KINETIC MODEL}

This new kinetic model was developed to account for the type of bond scission and the state of scission of the polymeric chain at any time. It was assumed that the probability of three polymer segments simultaneously colliding could be ignored. Therefore the overall thermal degradation rate of the polymer at any time could be represented as a combination of zeroorder, first-order, and second-order reactions. Physically, a zero-order reaction would reflect monomer scission from the polymer chain end (depropagation), small molecule scission from a

Table II Symbolic Meaning and Phosphorus Content of Blended Samples

\begin{tabular}{|c|c|c|c|}
\hline Code & $\begin{array}{c}\text { Weight } \\
\text { Ratio } \\
\text { (PMMA/FR) }\end{array}$ & $\begin{array}{c}\mathrm{P}^{\mathrm{a}} \\
(\mathrm{wt} \%)\end{array}$ & $\begin{array}{c}\mathrm{P}^{\mathrm{b}} \\
(\mathrm{wt} \%)\end{array}$ \\
\hline PMMA0F & $10: 0$ & 0.00 & $<0.01$ \\
\hline PMMA1F & $10: 1$ & 2.01 & 2.01 \\
\hline PMMA2F & $10: 2$ & 3.68 & 3.70 \\
\hline FR & $0: 10$ & 22.1 & 22.1 \\
\hline
\end{tabular}

\footnotetext{
${ }^{\text {a }}$ Phosphorus content from composition calculation.
}

${ }^{\mathrm{b}}$ Phosphorus content by colorimetry. side chain, or cyclization. A first-order reaction would reflect intramolecular transfer and random scission of the main chain; and a secondorder reaction, weight loss related to two random polymer segments colliding simultaneously, such as intermolecular transfer and scission. The thermal degradation rate equation which accounted for each of these three reaction orders was then written as follows:

$$
\begin{aligned}
\frac{d \alpha}{d t}=\beta & \cdot \frac{d \alpha}{d T} \\
& =K_{0 i}+K_{1 i}(1-\alpha)+K_{2 i}(1-\alpha)^{2}
\end{aligned}
$$

where $\beta$ is the heating rate; $\alpha$ is the weight loss fraction; $d \alpha / d t$ is the thermal degradation rate at any time; $d \alpha / d T$ is the thermal degradation rate at any temperature; $K_{0 i}$ is the summation of rate constants that belong to the zero-order reactions; $K_{1 i}$ is the summation of rate constants that belong to the first-order reactions; and $K_{2 i}$ is the summation of rate constants that belong to the secondorder reactions.

Each of the above three rate constants change, depending on the reaction temperature (or time). They also change depending on the chain scission, coupling, and cyclization which take place over the time period of the thermal degradation process. In order to solve eq. (1) simply, the following assumptions were made:

1. Equation (1) is a continuous function during the thermal degradation process. 


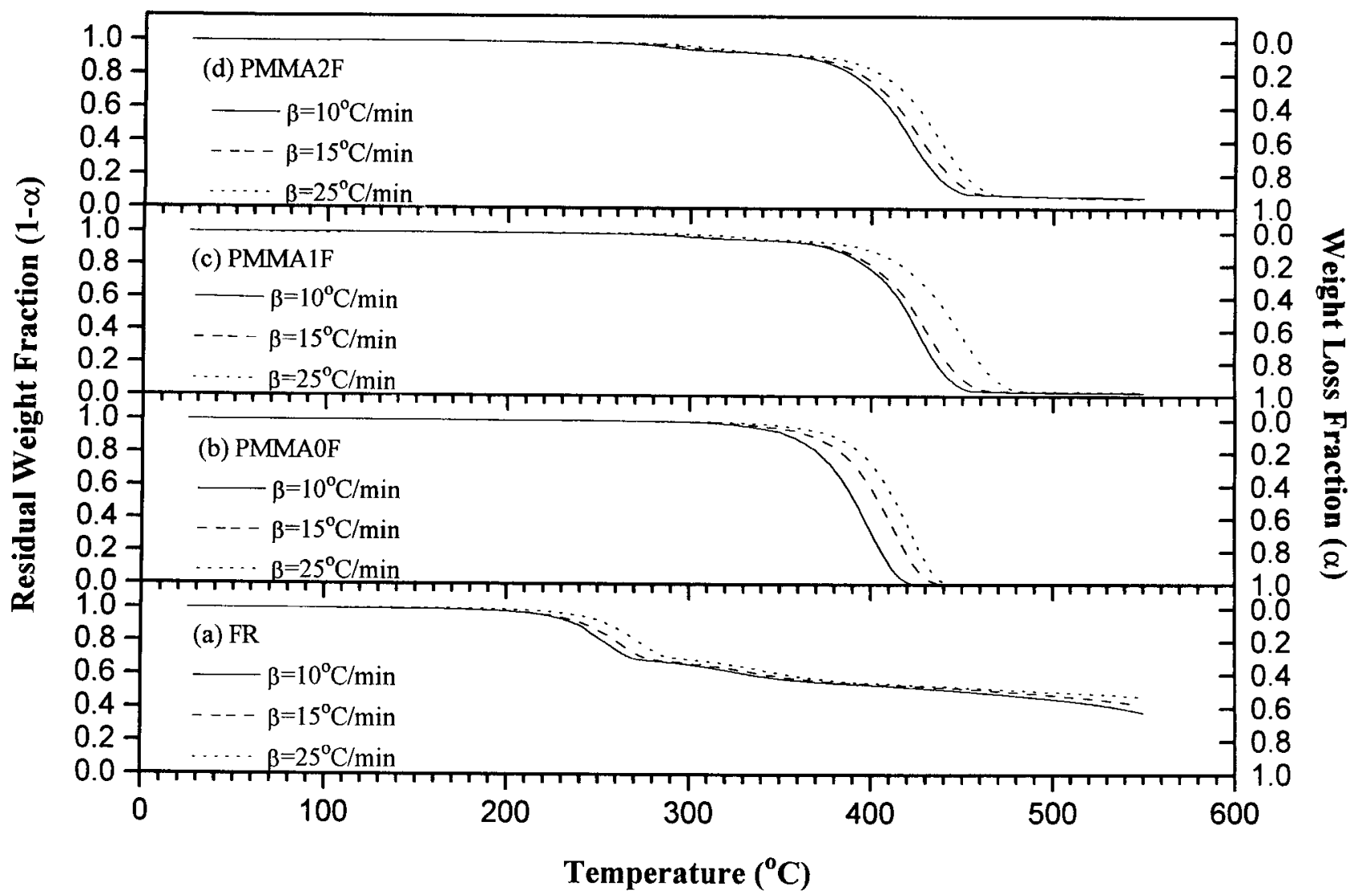

Figure 1 TGA thermograms of FR, PMMA, and their blends at different heating rates under nitrogen atmosphere.

2. The rate constant at any weight loss fraction, $\alpha$, is approximately equal to the rate constant of its neighboring weight loss fraction.

$$
\begin{aligned}
& K_{0 i, \alpha-\Delta \alpha} \approx K_{0 i, \alpha} \approx K_{0 i, \alpha+\Delta \alpha} \\
& K_{1 i, \alpha-\Delta \alpha} \approx K_{1 i, \alpha} \approx K_{1 i, \alpha+\Delta \alpha} \\
& K_{2 i, \alpha-\Delta \alpha} \approx K_{2 i, \alpha} \approx K_{2 i, \alpha+\Delta \alpha}
\end{aligned}
$$

3. All of the rate constants are greater than

$$
\begin{aligned}
& \beta\left[\begin{array}{c}
\frac{d(\alpha-\Delta \alpha)}{d T} \\
\frac{d \alpha}{d T} \\
\frac{d(\alpha+\Delta \alpha)}{d T}
\end{array}\right]_{\alpha} \\
& =\left[\begin{array}{ccc}
{[1-(\alpha-\Delta \alpha)]^{0}} & {[1-(\alpha-\Delta \alpha)]^{1}} & {[1-(\alpha-\Delta \alpha)]^{2}} \\
{[1-\alpha]^{0}} & {[1-\alpha]^{1}} & {[1-\alpha]^{2}} \\
{[1-(\alpha+\Delta \alpha)]^{0}} & {[1-(\alpha+\Delta \alpha)]^{1}} & {[1-(\alpha+\Delta \alpha)]^{2}}
\end{array}\right]\left[\begin{array}{c}
K_{0 i}\left(T_{\alpha}\right) \\
K_{1 i}\left(T_{\alpha}\right) \\
K_{2 i}\left(T_{\alpha}\right)
\end{array}\right] \cdot u\left(T-T_{\alpha}\right)
\end{aligned}
$$


or

$$
\beta\left[\frac{d \alpha}{d T}\right]_{\alpha}=[f(\alpha)][K] u\left(T-T_{\alpha}\right)
$$

where $[K]$ is the matrix of rate constants; $[f(\alpha)]$ is the matrix of concentration; and $u\left(T-T_{\alpha}\right)$ is the unit function at $T=T_{\alpha}$.

Solving for the matrix of rate constants, eq. (6) was obtained:

$$
\begin{aligned}
\therefore[K] & =\left[\begin{array}{l}
K_{0 i}\left(T_{\alpha}\right) \\
K_{1 i}\left(T_{\alpha}\right) \\
K_{2 i}\left(T_{\alpha}\right)
\end{array}\right]=[f(\alpha)]^{-1} \beta\left[\frac{d \alpha}{d T}\right]_{\alpha} \\
& \beta\left[\begin{array}{ccc}
{[1-(\alpha-\Delta \alpha)]^{0}} & {[1-(\alpha-\Delta \alpha)]^{1}} & {[1-(\alpha-\Delta \alpha)]^{2}} \\
{[1-\alpha]^{0}} & {[1-\alpha]^{1}} & {[1-\alpha]^{2}} \\
{[1-(\alpha+\Delta \alpha)]^{0}} & {[1-(\alpha+\Delta \alpha)]^{1}} & {[1-(\alpha+\Delta \alpha)]^{2}}
\end{array}\right]\left[\begin{array}{c}
\frac{d(\alpha-\Delta \alpha)}{d T} \\
\frac{d \alpha}{d T} \\
\frac{d(\alpha+\Delta \alpha)}{d T}
\end{array}\right]
\end{aligned}
$$

In order to compare this model with the experimental work of other authors, we defined

$$
P_{0}=\frac{K_{0 i}}{K_{0 i}+K_{1 i}(1-\alpha)+K_{2 i}(1-\alpha)^{2}}
$$

$$
\begin{aligned}
& P_{1}=\frac{K_{1 i}(1-\alpha)}{K_{0 i}+K_{1 i}(1-\alpha)+K_{2 i}(1-\alpha)^{2}} \\
& P_{2}=\frac{K_{2 i}(1-\alpha)^{2}}{K_{0 i}+K_{1 i}(1-\alpha)+K_{2 i}(1-\alpha)^{2}}
\end{aligned}
$$

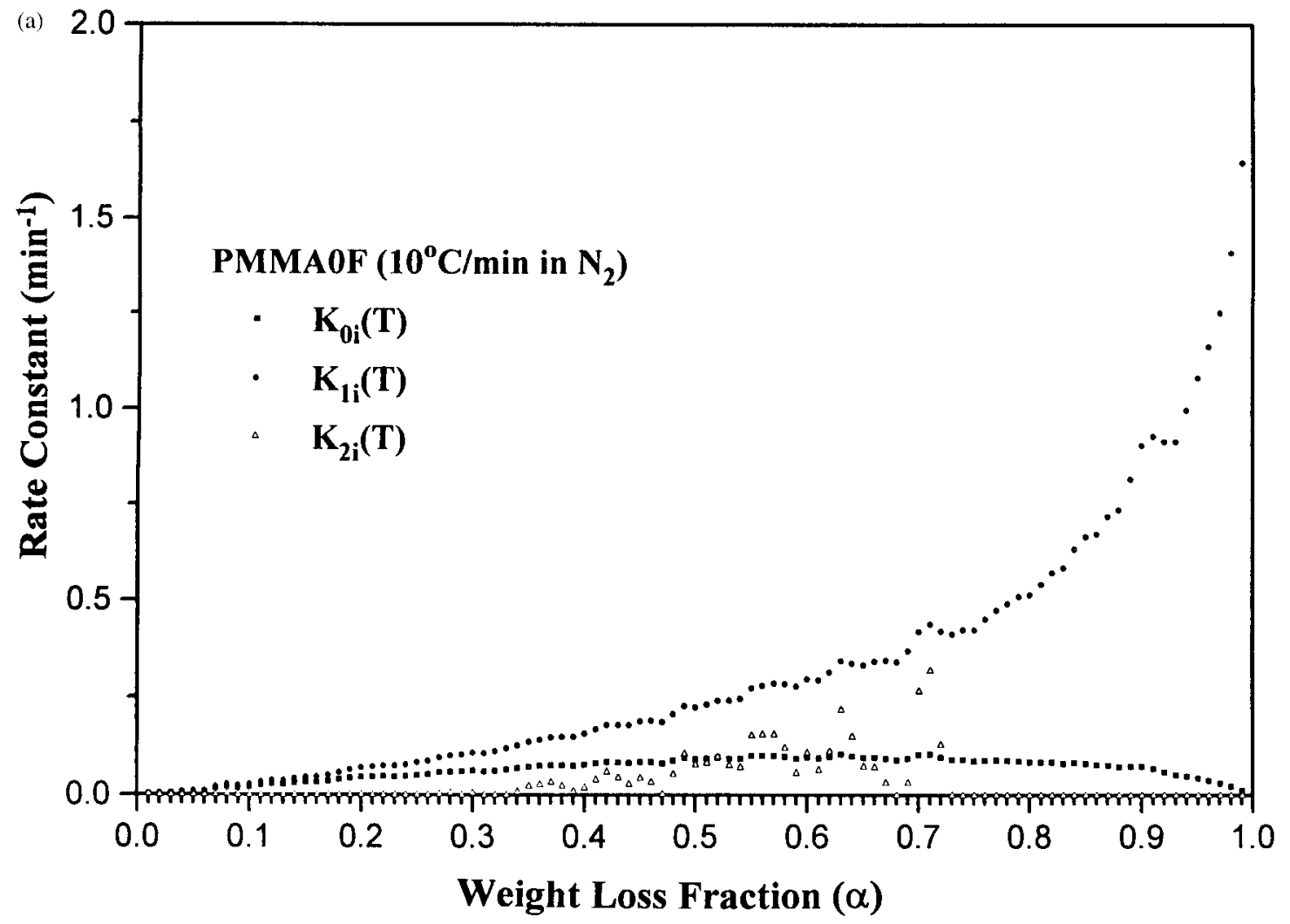

Figure 2 Relationship between the rate constant of different reaction order and weight loss fraction at a heating rate of $10^{\circ} \mathrm{C} / \mathrm{min}$ under nitrogen atmosphere for (a) PMMA0F, (b) PMMA1F, and (c) PMMA2F. 

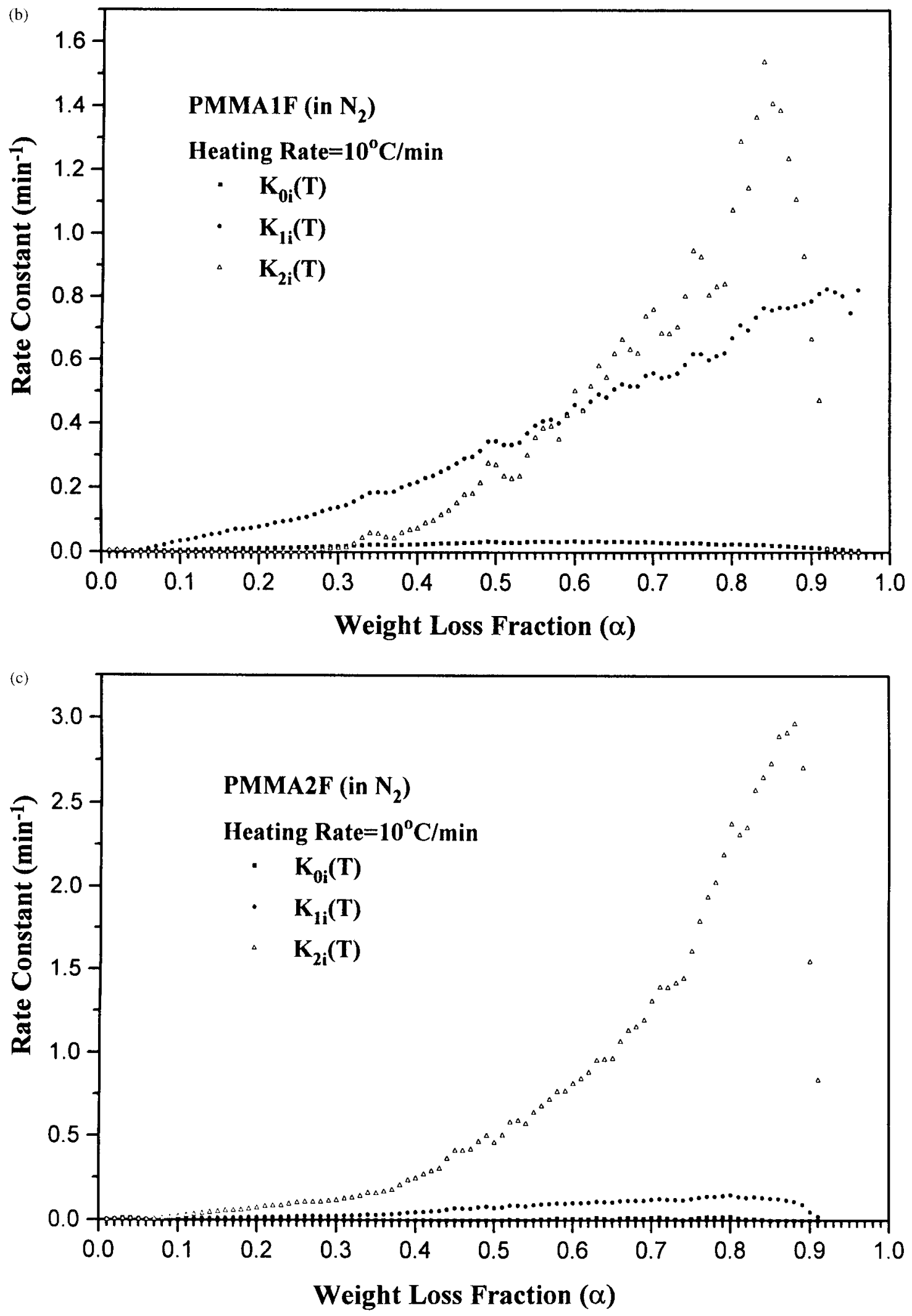

Figure 2 (Continued from the previous page) 

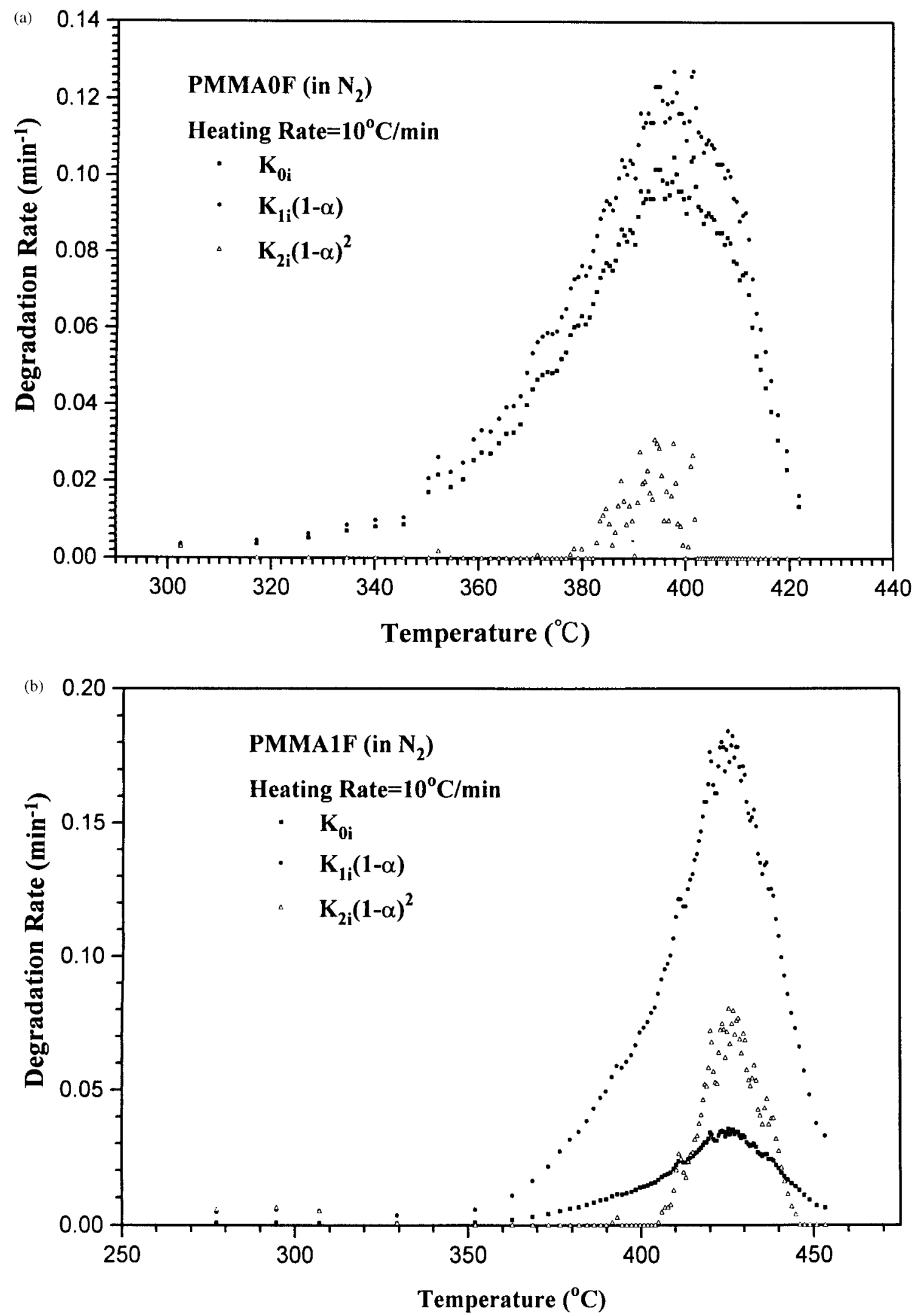

Figure 3 Thermal degradation rate of different reaction order as a function of temperature at a heating rate of $10^{\circ} \mathrm{C} / \mathrm{min}$ under nitrogen atmosphere for (a) PMMA0F, (b) PMMA1F, and (c) PMMA2F. 


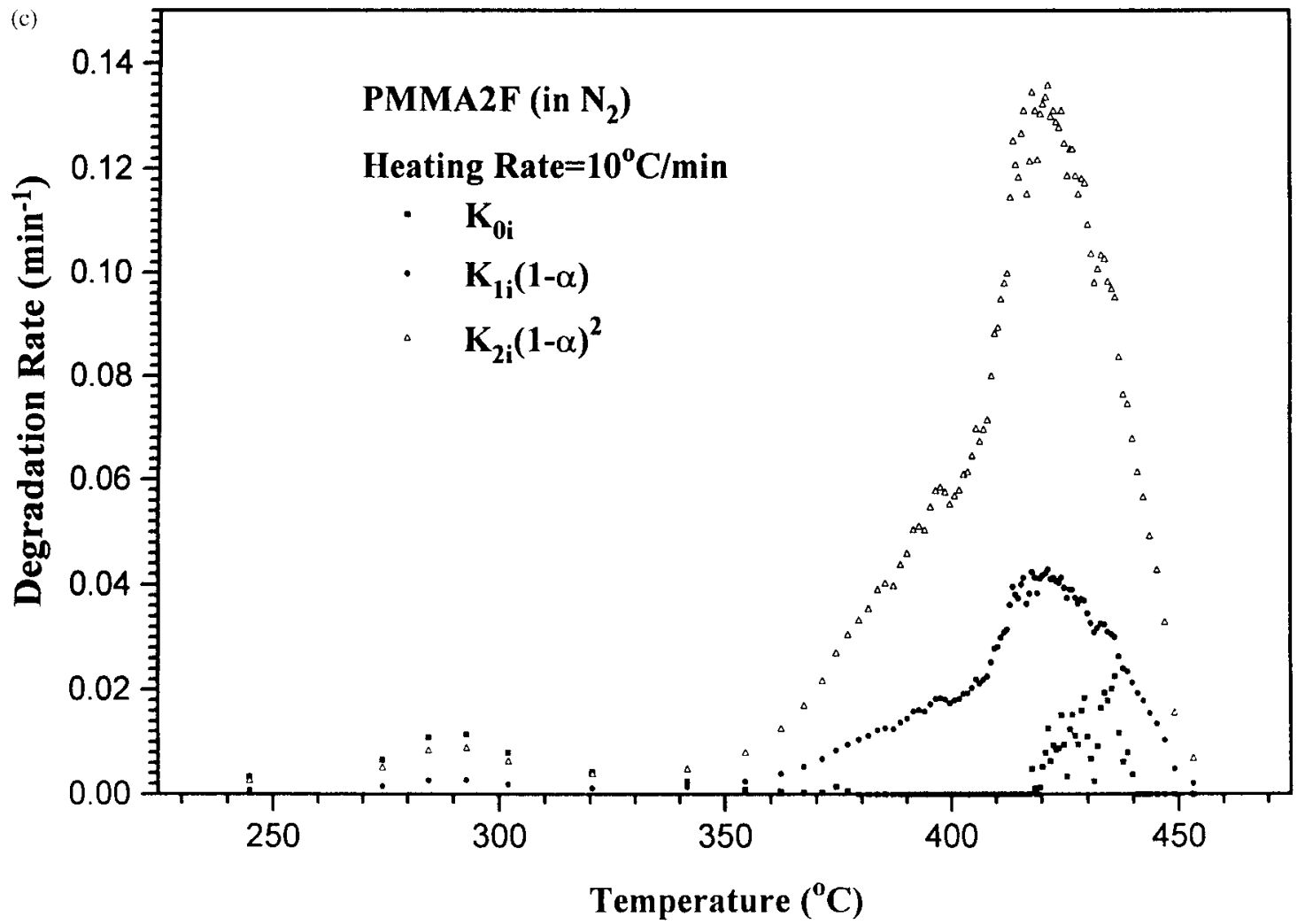

Figure 3 (Continued from the previous page)

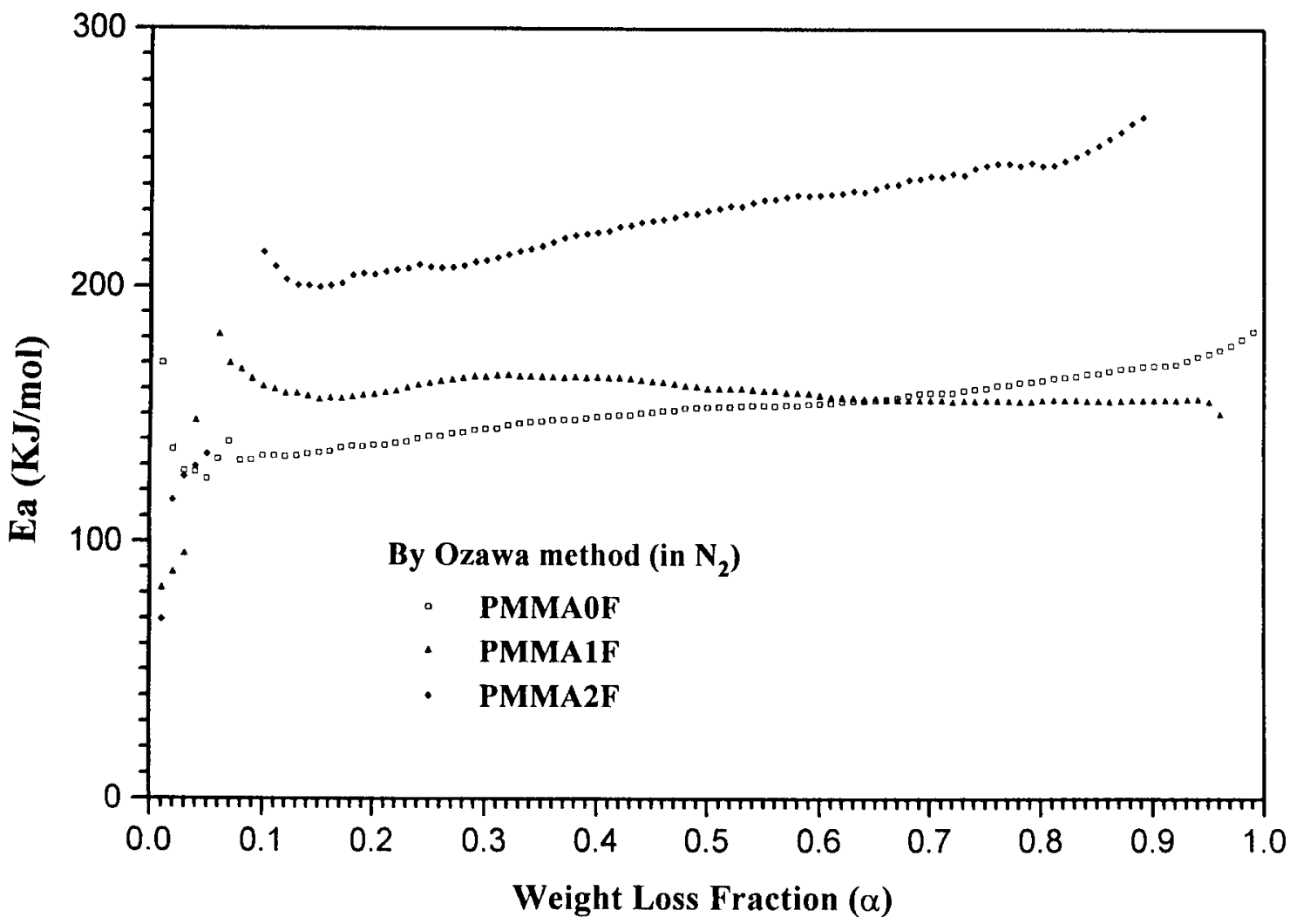

Figure 4 Relationship of activation energy versus weight loss fraction for PMMA blends, calculated by using Ozawa's method. 

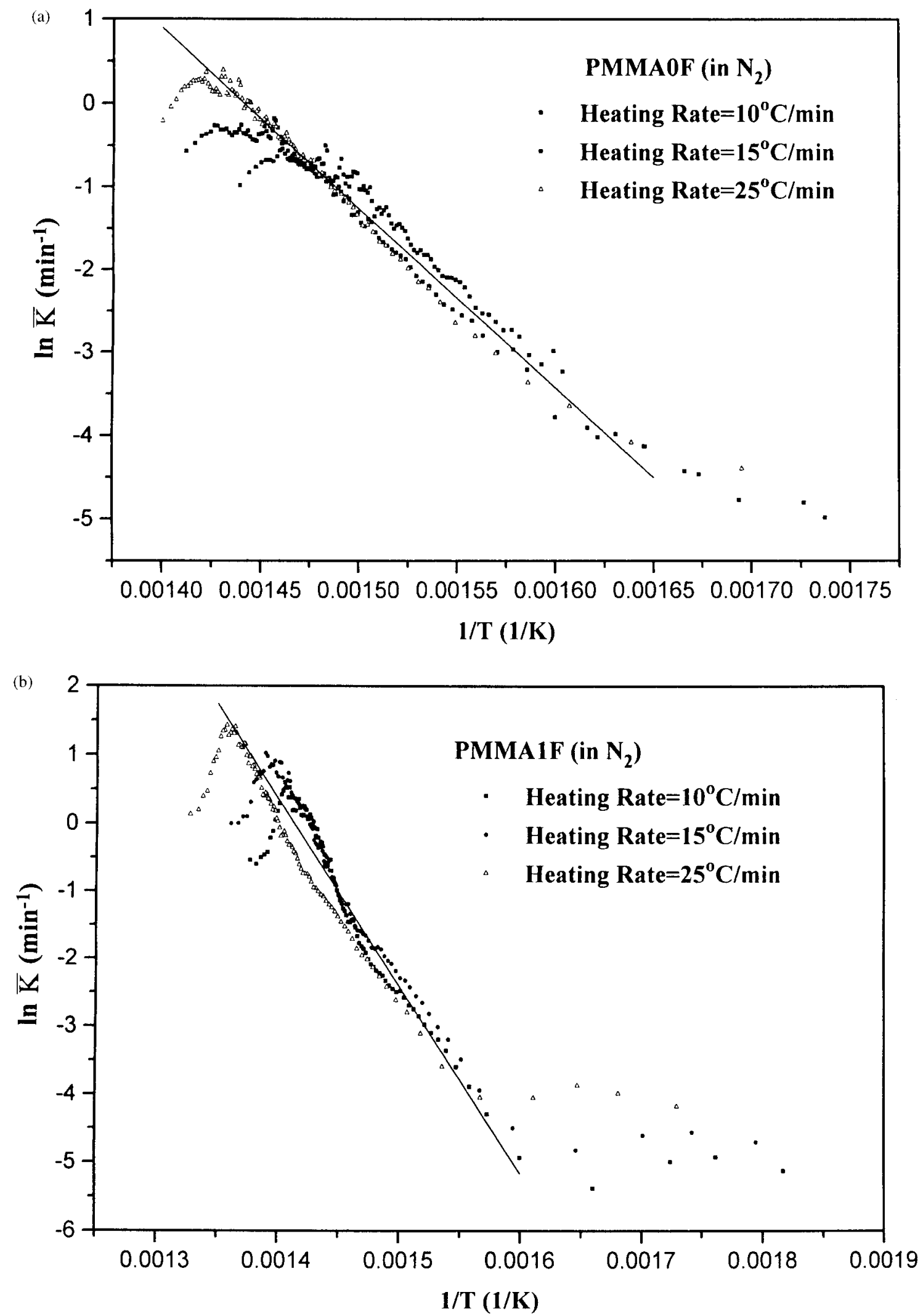

Figure 5 Arrhenius plot of logarithmic value of average reaction rate constant versus inverse of temperature at different heating rates for (a) PMMA0F, (b) PMMA1F, and (c) PMMA2F. 


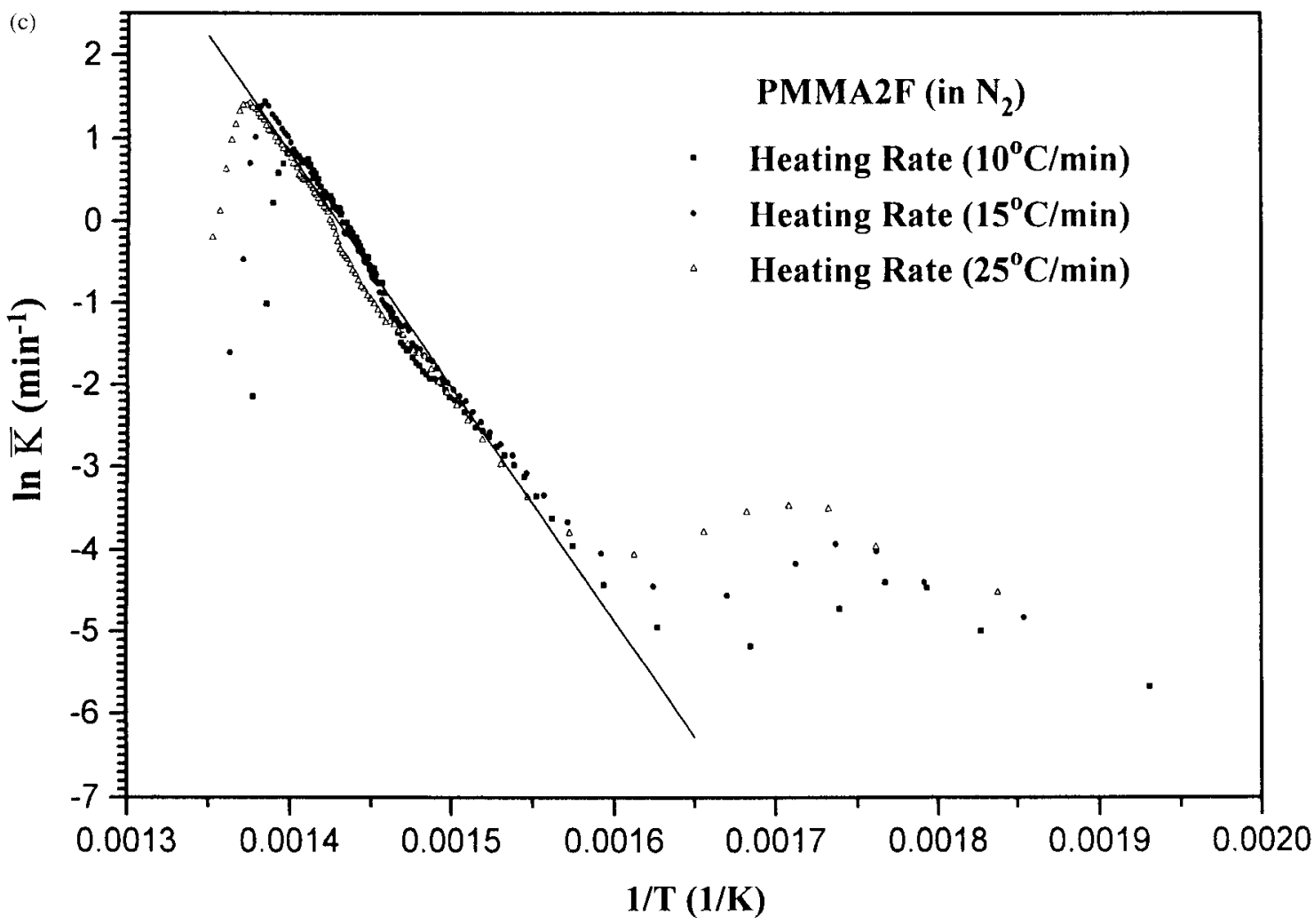

Figure 5 (Continued from the previous page)

$$
\begin{gathered}
\bar{n}=\sum_{n=0}^{2} n P_{n} \\
\bar{K}=\frac{\beta\left(\frac{d \alpha}{d T}\right)}{(1-\alpha)^{\bar{n}}}
\end{gathered}
$$

Here $P_{0}, P_{1}$, and $P_{2}$ are the relative contributions to the entire thermal degradation rate for the zero-, first-, and second-order reactions, respectively; and $\bar{n}$ and $\bar{K}$ are the averaged reaction order and rate constant, respectively. Finally, the activation energy was calculated from $\bar{K}$ and temperature $(T)$ using the Arrhenius equation.

\section{EXPERIMENTAL}

\section{Blending Material}

The samples were prepared from mixtures of PMMA supplied by Chi Mei Industrial Co. Ltd. (Taiwan, R.O.C.), and FR by the Chang Shan Institute of Science and Technology (Taiwan, R.O.C.). Samples were mixed in acetone and prepared at room temperature by a solvent-casting technique. The cast films were dried slowly in an oven at $106^{\circ} \mathrm{C}$ until the weight of the specimens remained unchanged. The physical properties of PMMA and FR are listed in Table I, and the symbolic meanings of the formulations used in this study appear in Table II. The phosphorus content of the PMMA blends was determined using a colorimeter, ${ }^{7}$ and the results are listed in Table II.

\section{Thermal Degradation Analysis of PMMA and Its Blends}

The thermal degradation of the PMMA blends was investigated by TGA with a Perkin-Elmer TGA-7 thermogravimetric analyzer at various heating rates under a nitrogen atmosphere. Kinetic parameters were calculated from eqs. (1)(11) on a VAX workstation using FORTRAN.

\section{RESULTS AND DISCUSSION}

\section{Kinetics of Thermal Degradation of PMMA and Its Blends}

In our previous study, ${ }^{8}$ the relationship between residual weight fraction $(1-\alpha)$ [or weight loss fraction $(\alpha)$ ] and temperature of PMMA blends at different heating rates under nitrogen atmo- 

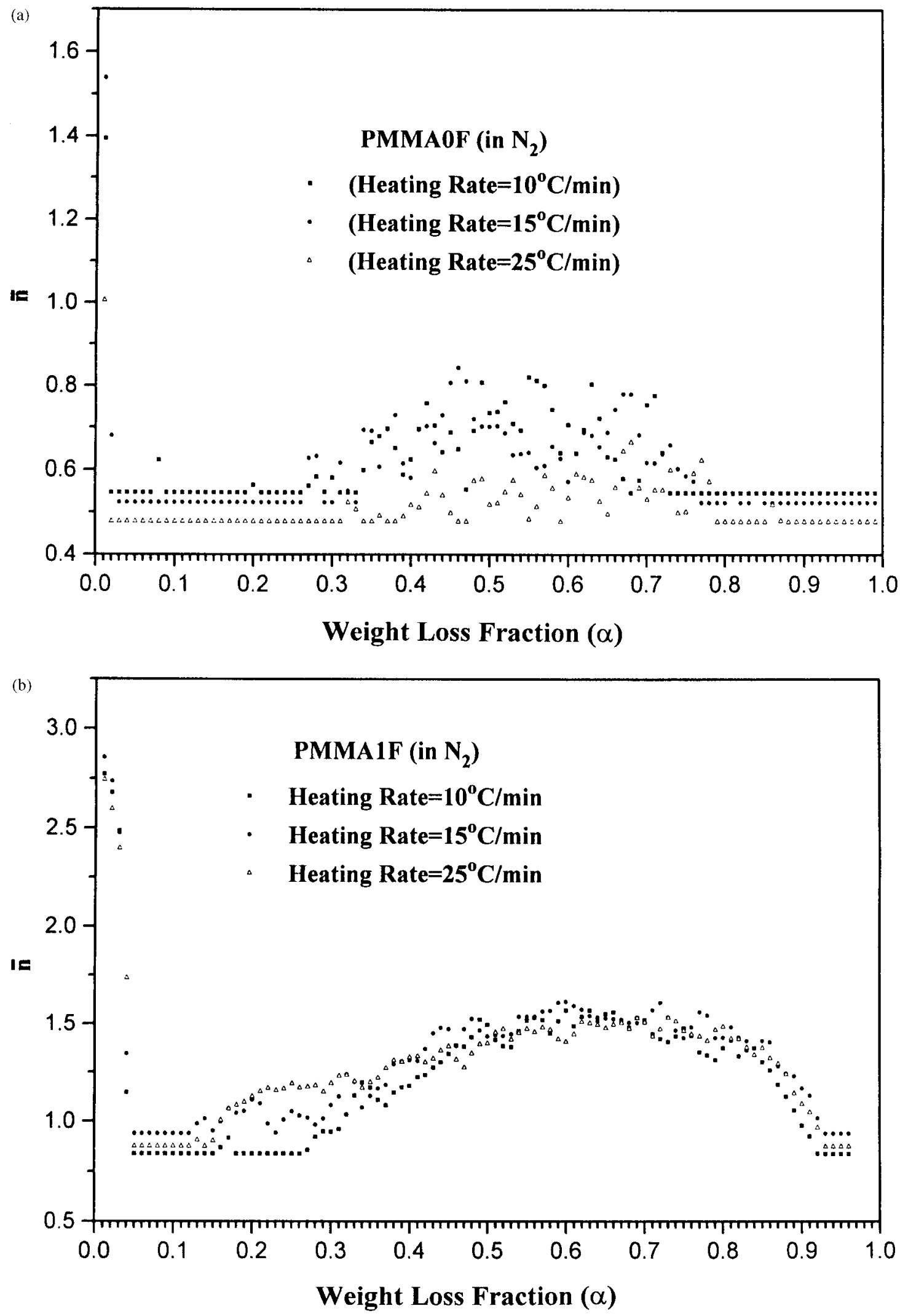

Figure 6 Relationship of average reaction order and weight loss fraction $(\alpha)$ at different heating rates for (a) PMMA0F, (b) PMMA1F, and (c) PMMA2F. 


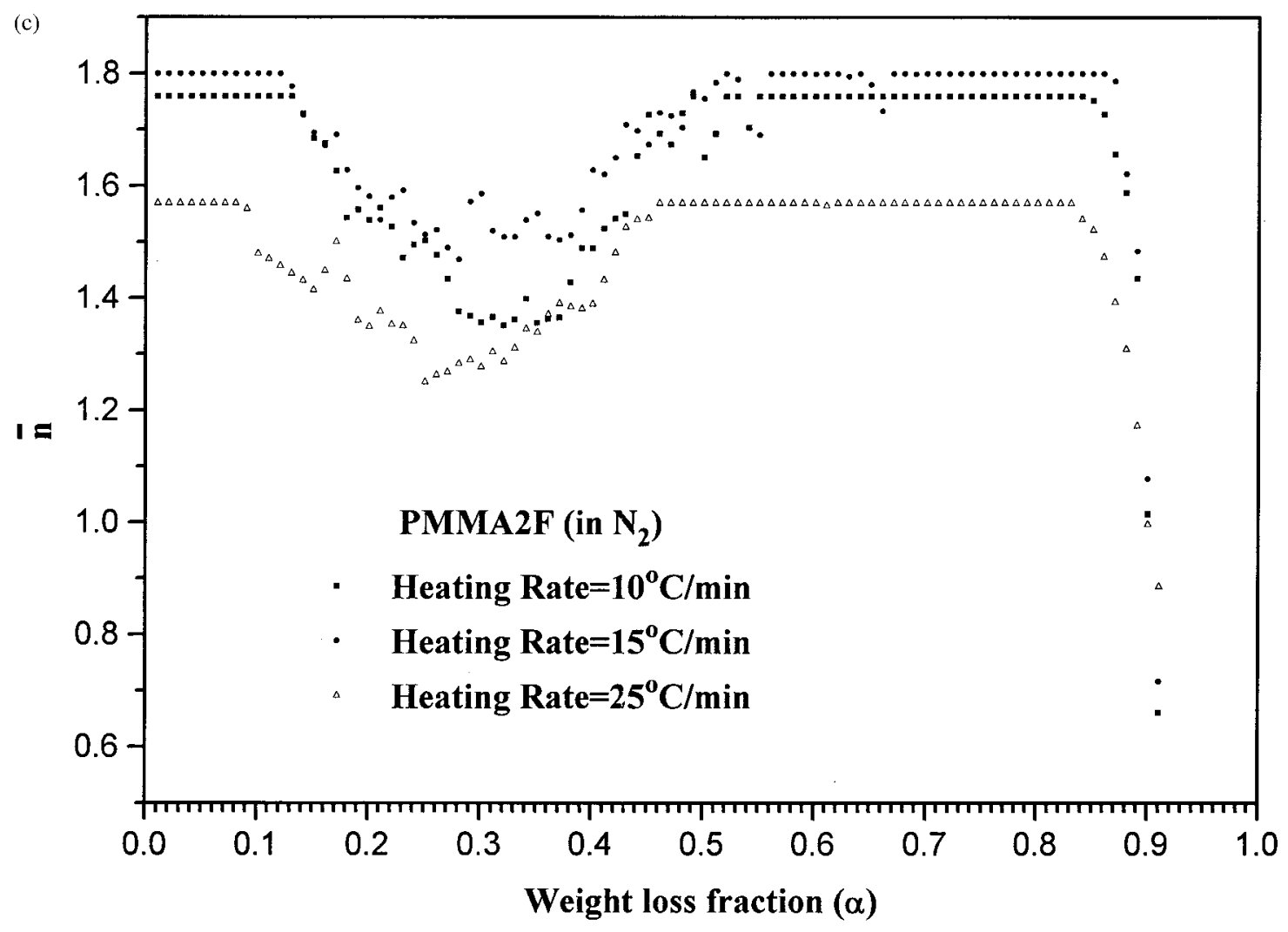

Figure 6 (Continued from the previous page)

sphere was determined as illustrated in Figure 1. Important phenomena during the thermal degradation of PMMA blends were found, such as a reduction in the initial thermal degradation temperature of PMMA blends relative to pure PMMA and an increase in the major degradation temperature and residual char yield at $550^{\circ} \mathrm{C}$ with increasing levels of FR. These phenomena are explained as being due to the formation of anhydride from the ester group of MMA during the thermal degradation of PMMA blends. The PMMA blends also showed an increase in their major thermal degradation temperatures with increasing of the heating rate due to a thermal lag effect, and, lastly, they showed similar TGA thermograms, which indicate that their thermal degradation mechanism was similar at different heating rates.

Using our proposed model, the relationship between the rate constants, separated by reaction order, and weight loss fraction is shown in Figure 2 . The heating rate here was $10^{\circ} \mathrm{C} / \mathrm{min}$ and thermal degradation took place in a nitrogen atmosphere. The contribution to the thermal degradation rates for different reaction orders in our PMMA blends is shown in Figure 3 as a function of temperature. In Figure 3(a) the contribution to the thermal degradation rate for PMMA0F is $1^{\circ}>0^{\circ}>2^{\circ}$; note that the zero-order contribution is close to the first-order contribution. The contribution to the thermal degradation rate from the second-order reactions was obvious only at high temperature. According to our proposed model, the thermal degradation rate contributed from the zero-order reaction indicates the scission of small molecule at side chains or cyclization or monomer breaking away from polymer chain ends. The thermal degradation rate contribution from the first-order reaction indicates the weight loss due to the random scission at various locations on the main chain; and the thermal degradation rate contribution from the second-order reaction indicates the weight loss related to the intermolecular transfer and scission. Considering that our sample materials were polymerized by free radical polymerization, and that current literature points out that during the thermal degradation process the important degradation mechanisms include depropagation, random main chain scission, intra- or intermolecular transfer, and the scission of small molecules from side chains, the thermal degradation rate data obtained from our model are reasonable and in agreement with the literature. ${ }^{9,10}$

The relationship between temperature and the thermal degradation rates contributed by differ- 
ent reaction orders for PMMA1F is shown in Figure $3(\mathrm{~b})$. The results indicate that the thermal degradation rate of the first-order reaction was always greater than both the zero-order and the second-order reactions; also that the thermal degradation rate of the second-order reaction was greater than the zero-order reaction only over the temperature range from 415 to $445^{\circ} \mathrm{C}$. At other times the thermal degradation rate contributed from the zero-order reaction was greater than the second-order reaction. In comparison with the results for PMMA0F, the thermal degradation rate contributed from the zero-order reaction, due to monomer breaking away from the polymer chain end, was drastically decreased as a result of adding FR. The reason for this decrease was the formation of an anhydride structure from the reaction of FR with the ester groups of PMMA which, in turn, restrained monomer scission from the polymer chain. As for the second-order thermal degradation rate, its contribution was due to the generation of shorter polymer fragment radicals at high temperature from random scission, which then caused weight loss through intermolecular transfer and scission. For PMMA2F, the relationship between thermal degradation rates and temperature for the different reaction orders is shown in Figure 3(c). Here, the thermal degradation behavior of PMMA2F depends on the temperature range. In the temperature range below $350^{\circ} \mathrm{C}$ the contribution to the thermal degradation rate from the zero-order reaction was greater than both the second-order and the first-order reactions. This phenomenon was observed from the analysis of the evolved gases and the residual yield in our previous study ${ }^{8,11}$ using TGA coupled with Fourier transform infrared spectroscopy and mass spectroscopy, respectively. In that study it was determined that the evolved gas was mainly propylene and methanol. The propylene resulted from the thermal degradation of FR, whereas methanol resulted from the formation of anhydride between FR and ester groups of PMMA. In the range above $350^{\circ} \mathrm{C}$ the number of anhydride structures formed in PMMA2F was greater than in PMMA1F, which restricted direct chain scission of monomer from chain ends. For this reason the contribution to the thermal degradation rate from the zero-order reaction was smaller than PMMA1F and PMMA0F. The ratio of anhydride and remaining MMA for PMMA2F could be calculated as follows ${ }^{12,13}$ :

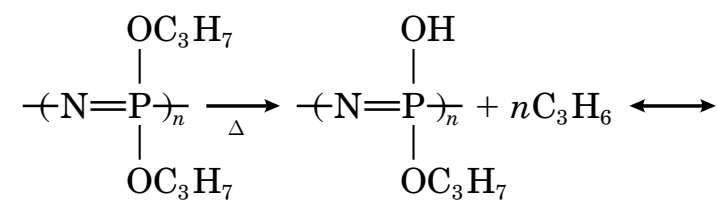

(I) (II)

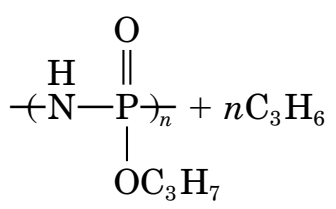

(III)

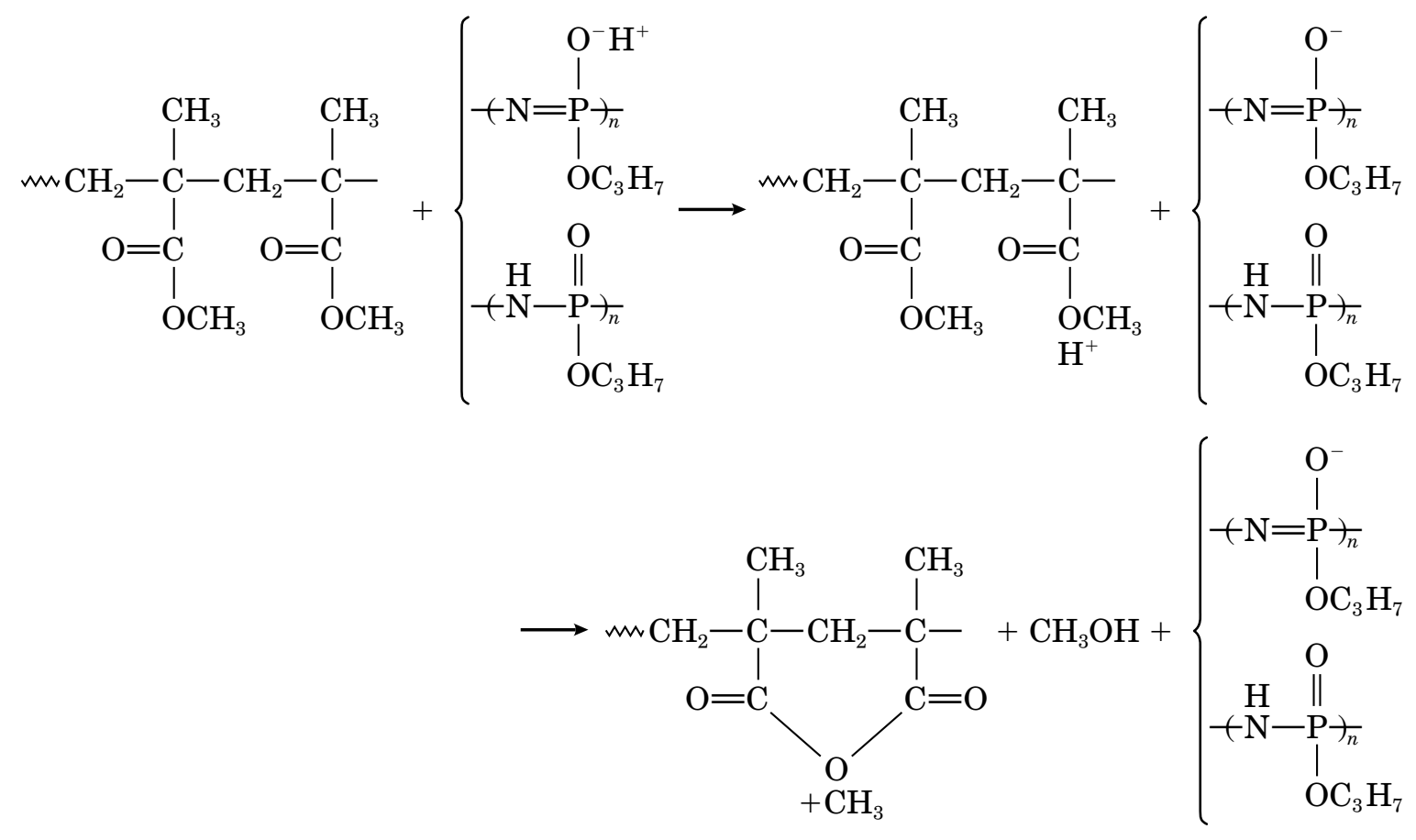


repeat number of MMA which

formed anhydride structures

repeat number of

remaining MMA structures

$$
=\frac{\frac{20}{163} \times 4}{\frac{100^{(a)}}{100^{(b)}}-\frac{20}{163} \times 4} \risingdotseq \frac{1}{1}
$$

where $100^{\text {(a) }}$ is the amount of PMMA in polymer blend; $100^{(\mathrm{b})}$ is the molecular weight of one unit of MMA; 20 is the amount of FR in the polymer blend; 163 is the molecular weight of a propyl ester phosphazene unit,

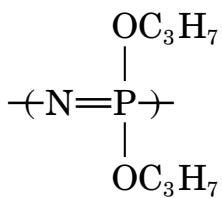

and 4 is the maximum repeat number of MMA reacted with one unit of $\mathrm{FR}$ to form anhydrides.

From the above calculation, the maximum probability of the formation of anhydride structure during the thermal degradation of PMMA2F was about $50 \%$. This indicated that above $350^{\circ} \mathrm{C}$ the amount of the anhydride was obviously much increased by the addition of $20 \mathrm{phr}$ of FR and explained the reduction in the zero-order contribution as a decrease in the amount of MMA monomer broken from the polymeric chain end. The large contribution from the second-order reactions above $350^{\circ} \mathrm{C}$ resulted from random main chain scission in PMMA2F generating shorter and more stable molecules than in PMMA0F and in PMMA1F. This encouraged the intermolecular transfer and scission.

In our previous study, ${ }^{8}$ the relationship between apparent activation energy and weight loss fraction $(\alpha)$ was studied using Ozawa's method ${ }^{14}$ as shown in Figure 4, and the results showed that the activation energies of PMMA0F, PMMA1F, and PMMA2F were about 154, 170, and $220 \mathrm{~kJ} /$ mol, respectively. In this article, the relationship between the average thermal degradation rate constant of PMMA blends versus temperature, using our proposed method, is shown in Figure 5. From this information the average apparent activation energy of PMMA blends was calculated using the Arrhenius equation; the results were 180, 229, and $237 \mathrm{~kJ} / \mathrm{mol}$ for PMMA0F, PMMA1F, and PMMA2F, respectively. The results calculated us- ing our model were slightly higher than those from Ozawa's method but still within the values reported in the literature, ${ }^{15-17}$ which hints that our proposed model is reasonable and correctly describes the thermal degradation mechanisms. In addition, the relationship between average reaction order of PMMA blends and weight loss fraction $(\alpha)$ is shown in Figure 6. These graphs show that the reaction order of PMMA blends increases with increasing the content of FR.

\section{CONCLUSIONS}

1. A new kinetic model was developed to describe the thermal degradation behavior of polymers, which accounted for the effects of parallel competitive reactions and the effects of multi-order combined reactions.

2. The average apparent activation energy of PMMA0F was about $180 \mathrm{KJ} / \mathrm{mol}$ during the thermal degradation process, and the mechanism was dominated by the firstand zero-order reactions.

3. Addition of FR caused the contribution to the degradation rate from the first- and second-order reactions to become much more important than the contribution from the zero-order reactions. Also, the average apparent activation energy of PMMA blends was increased by the addition of FR.

4. The major thermal degradation temperature of PMMA blends increased with increasing the content of FR. This phenomenon was due to the formation of an anhydride structure from the ester group of MMA.

The authors thank Mr. Marc DeRosa for his English correction and the Chung Shan Institute of Science and Technology (CSIST), Taiwan, R.O.C., for their financial support.

\section{REFERENCES}

1. A. Jimenez, V. Berenguer, J. Lopez, and A. Sanchez, J. Appl. Polym. Sci., 50, 1565 (1993).

2. J. M. Salin and J. C. Seferis, J. Appl. Polym. Sci., 47, 847 ( 1993 ).

3. J.-D. Nam and J. C. Seferis, J. Polym. Sci., Polym. Phys. Ed., 30, 455 (1992).

4. J.-D. Nam and J. C. Seferis, J. Polym. Sci., Polym. Phys. Ed., 29, 601 (1991).

5. Z. S. Petrovic and Z. Z. Zavargo, J. Appl. Polym. Sci., 32, 4353 (1986). 
6. T. Ozawa, J. Thermal Anal., 39, 1117 (1993).

7. M. B. Tomson, J. P. Barone, and G. H. Nancollars, Atomic Absorption Newsletter, 16, 117 (1977).

8. B. L. Denq, Y. S. Hu, W. Y. Chiu, L. W. Chen, and Y. S. Chiu, Polym. Deg. Stab., to appear.

9. N. Grassie and G. Scott, Polymer Degradation and Stabilization, Cambridge University Press, Cambridge, 1985 , p. 31.

10. I. C. McNeill, in Developments in Polymer Degradation, Vol. 1, N. Grassie, Ed., Applied Science, London, 1977, p. 47.

11. B. L. Denq and W. Y. Chiu, Bulletin of the College of Engineering, National Taiwan University, 1996, submitted.

12. S. J. Maynard, T. R. Sharp, and J. F. Haw, Macromolecules, 24, 2794 (1991).

13. V. S. Papkov, M. N. IL'ima, D. R. Tur, and G. L. Slonimskii, Polym. Sci. USSR, 31, 2509 (1989).

14. T. Ozawa, Bull. Chem. Soc. Jpn, 38, 1881 ( 1965 ).

15. V. A. Brockhaus and E. Jenckel, Makromol. Chem., 18/19, 262 (1956).

16. S. L. Madorsky, J. Polym. Sci., 11, 491 (1953).

17. T. Hirata, T. Kashiwagi, and J. E. Brown, Macromolecules, 18, 1410 (1985). 